\title{
Risk Alma ve Eleştirel Düşünme Eğilimlerinde Doğa Macera Eğitimine Bağlı Değişimlerin İncelenmesi
}

\author{
Sırrı Cem Dinç \\ Nevşehir Hacı Bektaş Veli Üniversitesi Spor Bilimleri ve Teknolojisi Yüksekokulu, Nevşehir \\ scem.dinc@gmail.com \\ ORCID ID: http://orcid.org/0000-0001-6915-4540 \\ Fatma Saçlı Uzunöz \\ Nevşehir Hacı Bektaş Veli Üniversitesi Spor Bilimleri ve Teknolojisi Yüksekokulu, Nevşehir \\ fatmasacli@gmail.com \\ ORCID ID: http://orcid.org/0000-0002-2246-4952 \\ Burak Güneş \\ Nevşehir Hacı Bektaş Veli Üniversitesi Spor Bilimleri ve Teknolojisi Yüksekokulu, Nevşehir \\ gunesburak82@gmail.com \\ ORCID ID: http://orcid.org/0000-0002-6571-646X
}

Araştırma Makalesi

Geliş Tarihi: 25.11.2018 Revize Tarihi: 10.12.2018 Kabul Tarihi: 25.12.2018

\section{Atıf Bilgisi}

Dinç, S. C., Saçlı Uzunöz, F. ve Güneş, B. (2018). Risk alma ve eleştirel düşünme eğilimlerinde doğa macera eğitimine bağlı değişimlerin incelenmesi, Ahi Evran Üniversitesi Sosyal Bilimler Enstitüsü Dergisi, 4(2), 166182.

\section{ÖZ}

Araştırmanın amacı, risk alma ve eleștirel düşünme eğilimlerinde doğa macera eğitimine katılıma bağlı anlamlı değişimlerin olup olmadığını incelemektir. Araştırmaya 19 kadın ( $\bar{x}$ yaş=20.21 1.96$)$ ve 22 erkek ( xyaş $=19.9 \pm 1.41$ ) birey katılmıștır. Macera eğitimi 8 hafta birer saatlik kuramsal derslerin sonunda Aladağlar'da gerçekleştirilen doğa kampçılığı ve yürüyüşü, interaktif doğa oyunları ve zirve tırmanışını (3480m) içeren 5 günlük etkinliği kapsamıştır. Veriler eğitim öncesi ve sonrası DOSPERT-Kısa Formu ve KEDEÖile toplanmıştır. Verilerin analizinde, bağımsız gruplarda ve tekrarlı ölçümlerde t-testi kullanılmıştır. Katılımcıların etkinlik öncesi ve sonrası rekreasyonel alt boyutunda anlamlı artış $(\mathrm{t}=-2.82 ; \mathrm{p}<.01)$, etik alt boyutta ise anlamlı düşüş $(\mathrm{t}=2.09 ; \mathrm{p}<.05)$ belirlenmiştir. Eleştirel düşünmede ise analitiklik $(\mathrm{t}=-2.29 ; \mathrm{p}<.05)$, açık fikirlilik $(\mathrm{t}=-7.03 \mathrm{p}<.001)$, meraklılık $(\mathrm{t}=-3.23 ; \mathrm{p}<.05)$ alt boyutlarında ve toplam puanda $(\mathrm{t}=-5.38 ; \mathrm{p}<.001)$ artıș, kendine güven alt boyutunda düşüs $(\mathrm{t}=2.67 ; \mathrm{p}<.05)$ saptanmıștır. Risk alma toplam puanlarında; erkeklerin yüksek risk aldıkları $\left(\mathrm{t}^{1}=-5.53, \mathrm{p}<.001 ; \mathrm{t}^{2}=-2.61, \mathrm{p}<.05\right)$, eleştirel düşünmenin ise alt boyutlar ve toplam puanlar açısından cinsiyete göre farklılık göstermediği ( $>$ >.05) saptanmıştır. Sonuç olarak doğa macera eğitimlerinin özellikle rekreasyonel risk alma eğilimlerini arttırdığı, erkeklerin kadınlara göre risk alma eğilimlerinin daha yüksek olduğu, eğitimin eleştirel düşünme eğilimlerinde artışa neden olduğu ancak cinsiyetler arasında fark yaratmadığı söylenebilir.

Anahtar Kelimeler: Doğa macera eğitimi, risk alma, eleştirel düşünme.

\section{Investigation of Changes in Risk Taking and Critical Thinking Disposition Related to Outdoor Adventure Education}

\footnotetext{
ABSTRACT

The aim of the study was to examine whether there were meaningful changes in risk taking and critical thinking dispositions after the participation in outdoor adventure education. 19 female (Mage $=20.21 \pm 1.96$ ) and 22 male (Mage $=19.9 \pm 1.41$ ), participated in the study. The adventure education was a 5-day experience that included back-packing, outdoor challenge and summit climbing $(3480 \mathrm{~m}$.) after 8-week theoretical course one hour each. The data were collected as pre-posttest with DOSPERT and CCTDI. The t-test was used in data analysis. There was increase in recreational $(\mathrm{t}=-2.82 ; \mathrm{p}<.01)$, while decrease in ethical risk taking $(\mathrm{t}=2.09 ; \mathrm{p}<.05)$ of the DOSPERT from pre-test to post-test. There were increases in analyticity $(\mathrm{t}=-$ $2.29 ; \mathrm{p}<.05)$, open-mindedness $(\mathrm{t}=7.03 ; \mathrm{p}<.001)$, inquisitiveness $(\mathrm{t}=-3.23 ; \mathrm{p}<.05)$ and total scores $(\mathrm{t}=-5.38$; $\mathrm{p}<.001)$ while significant decrease in self-confidence $(\mathrm{t}=2.67 ; \mathrm{p}<.05)$ of CCTDI. It was seen that male participants had higher scores than females in risk taking in both measures $\left(\mathrm{t}^{1}=-5.53, \mathrm{p}<.001 ; \mathrm{t}^{2}=-2.61, \mathrm{p}<.05\right)$. There were no significant differences either in total scores of CCTDI according to gender ( $\mathrm{p}>.05)$. As a result,
} 
it can be said that outdoor adventure education had positive changes in risk taking and critical thinking dispositions at university students and male students took more risks than females in outdoor.

Keywords: Outdoor adventure education, risk taking, critical thinking.

\section{Giriş}

Dağlara tırmanan, mağaraların derinliklerine inen, akarsudan aşağı kano yapan, kayaklar üzerinde uzun süreli etkinliğe katılan veya alçak ve yüksek ip etkinliklerine katılan pek çok insan mevcuttur. Bir başka deyişle küresel ölçekte giderek artan büyüklükteki bir insan topluluğu farklı biçimdeki macera etkinliklerine katılmaktadır (Ewert, 2007). Macera rekreasyonu Brown (1989) tarafindan kontrol edilemeyen tehlike veya özellikleri içeren doğal ortamlarda özel olarak geliştirilmiş becerilerin ve kararların uygulanması yoluyla tasarlanan kasitlı mücadele veya meydan okuma durumları olarak tanımlanmıştır. Ewert ve Hollenhorst (1989) ise "belirli bir aktiviteyle kişisel özelliklerin bütünleştirilerek öz niteliklerin düzenlenmesi” olarak tanımlanmıştır. Dolayısıyla doğal şartlarda gerçekleştirilen tırmanma, iple iniş, rafting paraşütle atlama, kayak, mağaracılık, sörf, dağ bisikleti, aletli dalış gibi çok çeşitli aktiviteleri kapsar. Genel turizm ve rekreasyon pazarının bir parçası olarak macera rekreasyonu, son yıllarda hızlı büyüme gösteren bir sektördür. Bunun temel nedenleri arasında maceranın ticarileşmesi (Buckley, 2007) bir başka söylemle etkinlik hizmetlerinin ticari bir işletme çatısı altında sunulması, perakende reklamcılıkta ilgi çekici macera görüntülerinin kullanılması (Buckley, 2003) ve özellikle şehir insanının serbest zaman aktivitelerinde olumlu stres arayışına (Priest ve Gass, 2018) yönelik heyecan ve riskler yaşama arzusu yatmaktadır (Hardiman ve Burgin, 2011; Cater, 2006).

Macera arayışı olgusu ya kültürel gelişmenin doğal bir unsuru ya da sınırlarını zorlamayı seçenlerin kucakladığı yeni bir tür etkinlik halini almaktadır. Macera etkinlikleri bu anlamda toplumların kumaşına derinlemesine işleyen ilmekler haline gelmektedir (Ewert, 2007). Macera etkinlikleri yoluyla bireyler becerilerini, tercihlerini, geçmiş deneyim ve beklentilerini program hedefleriyle bütünleştirerek etkinliklerdeki belirsiz olan sonuçları üretebilmek için gerçek veya algılanan tehlikeleri, sosyal ve çevresel faktörleri birleştirirler (Ewert ve Hollenhorst, 1989; Ewert ve Sibthorp, 2014).

Doğa ve macera eğitimi ise doğal alanda gerçekleşen deneyimsel bir süreci içererek tüm duyuların kullanımını gerektiren bir öğretim yöntemidir. Dolayısıyla doğal kaynak ve insan ilişkilerini içeren disiplinler arası konuları inceler. Doğa ve macera eğitimi ağacı (Martin ve Priest, 1986) doğa eğitimini iki yaklaşımla açıklamaktadır. Macera yaklaşımları bireylerin karar alma güçlerini ve problem çözmede ortak çalışmayı geliştirmeye yöneliktir. Doğa yaklaşımları ise çevresel sorunlarla başa çıkma ihtiyacı içerisindedir. Yapılan çalışmalar bu iki yaklaşımın birbiriyle önemli ölçüde ilişkili olduğunu ve sürecin gerçek bir doğa deneyimini ortaya çıkardığını belirmektedir (Priest ve Gass, 2018). Doğa ve macera eğitimi bir yandan sosyal ve fiziksel çevreye uyumu geliştirirken bir diğer yandan problem çözmedeki özgüveni, özgür düşünceyi ve öğrenmeyi hızlandırmaktadır. Bilişsel ve duygusal gelişimin anahtarı niteliği taşıyan bu özellikler kişide sık karar verme, yargıda bulunma ve problemlere alternatif çözümler üretme becerilerinde gelişimi ortaya çıkarmaktadır (Priest ve Gass, 2018). Bir diğer söylemle doğal alanlardaki deneyimler yoluyla bireyler, doğal çevreyle olan ilişkilerini, doğal kaynakların çeşitli konseptlerini ve bireyler arası etkileşimin önemini daha çabuk kavrarlar.

Macera Deneyim Paradigması (Martin ve Priest, 1986), Flow (akış) fikrine dayanan (Csikszentmihalyi, 1992; Jones, Hollenhorst ve Perna, 2003) ancak özel olarak doğa ve macera etkinliklerine katılan bireylerin algıladıkları risk ve etkinliğe ilişkin bireysel yeterlilik dengelerine odaklanır (Martin ve Priest, 1986; Jones, Hollenhorst ve Perna, 2003; Priest ve Gass, 2018). Katılımcıların risk ve bireysel yetkinlik algıları, maceracıların "çevreyi (doğal ve sosyal) etkileme veya kontrol altında tutabilme yeteneklerini" ne kadar iyi gösterebildiklerine bağlıdır. Paradigmaya göre deneyimsiz katılımcılar etkinliği tehlikeli ve yüksek riskli algılarken deneyimliler, temel becerilerden çok daha karmaşık görünen becerilere sahip olduklarını düşündüklerinden, etkinlikteki riskleri ve tehlikeleri daha düşük algılamaktadırlar. Çünkü doğada yaşanabilecek zorlukları 
yenmelerine engel olan korkuların üstesinden gelebilmektedirler. Bu sayede yaşamı sürdürmenin kritik anlarında dikkat ve eylemlere odaklanabilmeyi sağlayan bir tür zihinsel dayanıklılık kazanmış ve bilişsel kontrol uygulama becerisi geliştirmişlerdir (Jones, Hollenhorst ve Perna, 2003). Macera eğitimi yoluyla bu türden yeni öğrenimlere nasıl ulaşılabileceğini tanımlamaya çalışan farklı kuramlar vardır. Bunlardan biri Walsh ve Golins (1976) tarafindan tanımlanan "Outward Bound Süreci"; macera eğitimini "yeni fiziksel ve sosyal çevre içerisinde özel birtakım problem çözme görevlerini içeren "uyarlanmış uyumsuzluk" durumu sayesinde kazanılan deneyim ve öğrenilenlerin anlamının yeniden kodlandığ 1 uzmanlaşma süreci” olarak açıklanmıştır. Bir diğer ifadeyle macera eğitim süreci, üstesinden gelebilmeleri için katılımcılara başarmaları istenen problem çözme görevleri sunan macera etkinliklerini (kış kampçılığı, dağ kampçılığı ve yürüyüşü, dağc1lık, kanoculuk gibi doğa sporları etkinlikleri, alçak ve yüksek ip teknikleri, vb.) içerir (Sibthorp, 2003). Etkinliklerden sağlanan deneyim yeni bilgilerde uzmanlaşma anlamına gelir ve görevlerin başarıyla tamamlanması durumlarda başlar. Katılımcı, bir durumdaki problemi çözdüğünde takımın bir parçası olduğu ve öz değerleriyle ilgili pozitif duygular hissederek ödüllendirilmiş olur. Bu uzmanlık gelişiminin ardında yatan amaç, başarılı stratejileri genellemek ve duyguları başka durumlarla ilişkilendirmektir. Çünkü transfer macera programlarının en kritik özelliklerinden biridir. Dolayısıyla görünüşte hedef ve amaçları farklı olan etkinlikler katılımcıların öz niteliklerini geliştirmek üzere yapılandırılabilirler. Dolayısıyla yabanıl ortamlardaki macera deneyimlerinde, etkin bilişsel yeniden yapılandırmaya izin vermek için etkinlikler sistematik olarak tasarlanabilir. Bunun sonucunda yeni oluşturulan kodlar, farkl1 performans becerilerini içerebilir, ancak benzer genel becerilerin kullanımını gerektirebilir. Bir başka söylemle kış şartlarında yaşamı sürdürme becerisini sergileyerek başarılı olan bir bireyin kazanacağ öz-yeterlik, farklı bir beceriye ilişkin yeni belirlenecek kodlara etki edebilir (Taniguchi, 2017). Ya da dağcılık eğitiminde edinilen deneyim eleştirel düşünce ve risk alma eğilimleri üzerinde etki yaratabilir. Çünkü yeni öğrenilecek her iki etkinlikte de bireylerin algılanan risklerle ilişkili stres ve korkularını yönetmeleri gerekmektedir. Birey yeni bir aktivite veya beceri alanını öğrenmede başarılı olduğu için, ustalık duygusu, birey yeni becerilere yaklaştığında kalıcılığı ve çabayı artıracaktır (Bandura, 1997).

"Macera etkinliklerinde deneyim ve tatmin amaciyla maceranın merkezinde rol alan risk, macera rekreasyonu programlarının içerisinde olmazsa olmaz özellik taşımakta ve eksikliği halinde bireylerin aktivitelere katılım isteğinde azalma yaratabilmektedir" (Weber, 2001, ss. 360-377; Dickson ve Dolnicor, 2004, ss.1-11). Macera içerisinde yer alan "risk algısı" bireyseldir. Deneyimin bir bölümünde riski algılayan birey için etkinlik riskleri; korku, heyecan arayışı ve ürpertinin bir birleşimidir. Bu noktada tehlikenin varlığı ile ortaya çıkan, değer verilen şeylerin kaybedilme potansiyeli olarak adlandırılan risk, rekreasyon içerisinde yer alan macera programlarında bireyleri etkinliğe yönlendiren temel nedenler arasında görülmektedir ve doğa sporları açısından da en dikkat çekici durumsal değişken olarak karşımıza çıkmaktadır (Dinç, 2006). Yüksek riskli spor katılımcıları genellikle ilgili riskleri kontrol altına alma ihtiyacından bahsetmektedir ve risk alma daha deneyimli olanlara karşı bir meydan okumayı temsil etmektedir (Fave, Bassi ve Massimini, 2003) Deneyim ve beceri düzeyleri arttıkça, macera etkinlikleri arasında sayılan kaya tırmanışında katılımcılar mücadele etmek ve optimum uyarılma seviyelerini korumak için daha riskli uygulama biçimlerine girmeye motive olabilirler (Franken, 1998). Bu nedenle, bazı dağcılar kasıtlı olarak riskli davranış alternatiflerine girebilirken, diğerleri riskleri olabildiğince azaltmak isteyebilir. Bugüne kadar, yüksek riskli sporlarda riskle ilgili davranış stratejilerinin yaygınlığı ve korelasyonları hakkında çok az bilgi bulunmaktadır (Llewellyna ve Sanchez, 2008) Macera Paradigması 1şığında bireyin düşünce yapısı doğrultusunda sahip olduğu deneyimi, etkinlik çevresinde değerlendirerek yetkinliğine bağlı riskleri alma hususunda karara varması eleştirel düşünme mekanizmasının gelişimine firsat verebilir.

Eleştirel düşünce de bireyin hem sosyal hem de doğal çevresiyle etkileşimi sürecinde herhangi bir konuda bir yargıda bulunmadan önce bilimsel olguları ve durumsal değişkenleri hesaba katmayı gerektiren bir düşünce biçimi olduğu ifade edilebilir (Şenşekerci ve Bilgin, 2008). Cüceloğlu (2008) başkalarının düşünce süreçlerini de dikkate alarak kendi düşüncelerimizin farkına vardığımız bir süreç olduğunu belirttiği eleştirel düşünceyi, etrafımızdaki olayları anlayabilmeyi hedefleyen aktif zihinsel bir süreç olarak bildirmektedir. Normal düşünce durumundan eleştirel düşünme stratejileri kullanmaya başlayan birey, evrensel entelektüel normlara uygun düşünce düzeyine ulaşır ve yaşama ve bulunduğu 
çevreye ilişkin rasyonel değerlendirmeler yapma ihtiyacı duyar (Paul ve Elder, 2001; Şenşekerci ve Bilgin, 2008). Düşünce sisteminde devrimsel bir süreç gerektiren eğilimler, yoğun bir çalışma ve kararlılık gerektiren eğitim yoluyla kazanılabilmekte ve geliştirilebilmektedir (Şenşekerci ve Bilgin, 2008). Eleştirel düşünmenin, yapılandırmacı ve eleştirel paradigma kapsamında yürütülen öğretim programları için gerekli bir unsur olduğu tartışma götürmez bir gerçektir. Tsangaridou ve O'Sullivan (1994) özellikle gelecekte, öğretim programlarını yönlendiren öğretmenler için de bağımsız olma ve eleştirel düşünme becerilerini geliştirmelerinin gerekli olduğunu ortaya koymuşlardır.

Bireyin bilişsel, fiziksel, sosyal, zihinsel, ruhsal ve duygusal becerilerinin gelişimini hareket yoluyla arttırmayı amaçlayan beden eğitiminde bu gelişim alanları arasındaki yoğun ilişki, eleştirel düşünmeyi beden eğitimi programları için vazgeçilmez bir bileşen yapmaktadır (Gillespie ve Culpan, 2000). Eleştirel düşünme becerileri özellikle Yaratıcı Dans ve Beden Eğitimi dersi öğretim programlarının temel öğesi olarak görülmektedir (Chen ve Cone, 2003). McBride (1992) 'ın belirttiği gibi özellikle bilişsel, psiko-motor ve duyuşsal alanın birbiriyle yakından ilgili olduğu beden eğitimi ve spor alanında öğrenim gören öğrencilerin eleştirel düşünme düzeylerinin yüksek olması ve bu becerileri öğretebilme yeteneklerini kazanmaları istenmektedir. Eleştirel düşünmenin beden eğitiminde kullanılması, geniş ve maceracı düşünme, yenilikçi çözümler bulma, nedensel ve değerlendirici bir akıl yürüterek kıyaslama yapma, planlı ve stratejik düşünme, üstbiliş kullanımı ve hareket ve zorluklar karşısında mantıklı ve savunulabilir kararlar almayı sağlar (McBride, 1992; Tishman ve Perkins, 1995).

Ülkemizdeki eleştirel düşünmenin yaygın çalışmaları yoğun olarak öğrencilerin ve gençlerin eleştirel düşünme profilleri öğretmenlik programlarında (Gülveren, 2007; Kökdemir, 2003; Özden, 2005); Beden Eğitimi ve Spor alanında (Mutlu, Polat, İlçin ve Kalkan, 2016; Saçlı ve Demirhan, 2008 ) çalış1lmıştır. Çalışmalar sonucunda üniversite öğrencilerinin eleştirel düşünme becerilerinin orta seviyede ve beklenen düzeyin altında olduğu ortaya konulmuştur. Doğa ve macera eğitim programlarına ilişkin herhangi bir çalışmaya rastlanmamıştır.

Öğrencilerin bu becerileri kazanmaları ve geliştirmeleri öğretmenin uygulayacağı eğitim ögretim ve yönlendirmeler yardımıyla sağlanabilecektir (Chen ve Cone, 2003). Günümüzde kullanılan eleştirel düşünme, özel bir öğretim konusundan ziyade öğrenim sürecine yayılmış "Kaynaştırma" modeliyle sunulmaktadır. Bu yaklaşımla içeriği belirlenmiş ve tümüyle arazi koşullarında kamp yaparak gerçekleştirilen doğa ve macera eğitimi, kaynaştırma yaklaşımı çerçevesinde araç olarak kullanılabilir. Çünkü eleştirel düşünme eğitim içerikleri bilişsel uyumsuzluk (Brookfield, 1995) yaratan, öğrencileri yapmak ve yaşamak istediklerine ilişkin karar almayı, etkin olmayı, olay ve olguları farklı bakış açısıyla incelemelerini (Şenşekerci ve Bilgin, 2008) sağlamaya yöneliktir. Bilginin yetersizliği gibi belirsizlik hallerindeki karar verme zorunluluğu ise zaman sinırlılığı, kestirme yol kullanımını ve yapılabilecek yanlışları uyumlu davranışlar haline sokmayı gerektirir (Tobena, Marks ve Dar, 1999). Macera eğitim programları da bu özellikleri işbirliğine dayalı grup çalışmasına adapte uyumsuzluk durumları geliştirerek sağlamaktadır (Priest ve Gass, 2018). Özellikle maceralı etkinlikler sürecinde eleştirel bakış açısını açığa çıkaracak temel unsurların alışık olunmayan fiziksel ve sosyal çevre, adapte uyumsuzluk durumları ve seçerek risk faktörü olduğu düşünülmektedir.

Doğa ve macera etkinlikleri günümüzde giderek daha popüler bir hal almasına (Pain ve Pain, 2005) rağmen katılım yoluyla kazanılan beceriler sonucu sağlanan deneyim ve doğal alanda yaşamayı gerektiren etkinliklerin içerdiği risk alma istekliliğiyle ilgili deneysel veriler oldukça sınırlı durumdadır. Bunlardan bazılarına ilişkin sonuçlar incelenecek olursa; farklı içerikteki doğa sporları ve macera eğitimlerie katılan üniversite öğrencilerinde etkinliğe ilişkin çekicilik algısında artış (Dinç, Koca, Demirhan ve Aşçı, 2004), öz etkililik puanlarında artış (Özen, Özen ve Sönmez, 2014), öz yeterlik algılarında önemli bir yükseliş (Constantine, 1993), heyecan, zorlanma/meydan okuma duygularında artış (Çetinkaya ve Ömüriş, 2017) kendine ve başkalarına güven, risk almada kararlılık gibi sosyal-psikolojik kazanımlar (Çelebi, 2002), nitel çalışma sonucunda becerilerinin, doğal çevrenin, yeteneklerinin farkına varma ve katılım arzusunda artı̧̧ gibi fiziksel kazanımlar elde 
ettiklerini belirtmişlerdir (Çelebi ve Akbaba, 2002). Bunun yanı sıra bireylerin sahip olduğu risk alma-algılama düzeylerinin bir deneyimden nasıl etkilediğine yönelik deneysel veriler ile farklı risk alma ve etkinlik yeterlilik seviyesindeki katılımcıların sahip olduğu bilişsel, duyuşsal ve psiko-motorik becerilerin belirlenmesine ilişkin betimsel veriler de ülkemizde halen çalışılmayı bekleyen başlıklar arasında yer almaktadır. Doğada sık karar verme ve problem çözme davranışlarını içeren macera etkinlik deneyimimnin eleştirel düşünme üzerindeki etkisine ilişkin herhangi bir veriye ise ulaşılamamıştır. Bu kapsamda çalışmanın amacı, risk alma ve eleştirel düşünme becerilerinde doğa macera eğitimine katılıma bağlı anlamlı değişimlerin olup olmadığını incelemektir.

\section{Araştırma grubu}

\section{Yöntem}

Araştırmaya tesadüfi olmayan örnekleme yöntemlerinden kasıtlı örnekleme yöntemiyle (Hayran ve Hayran, 2011) seçilmiş 19 kadın $\left(\bar{x}_{\text {yaş }}=20.21 \pm 1.96\right)$ ve 22 erkek $\left(\bar{x}_{\text {yaş }}=19.90 \pm 1.41\right)$ olmak üzere toplam 41 üniversite öğrencisi katılmıştır. Katılımcılar üniversite eğitim programında ortak seçmeli dersler bünyesinde yer alan ve kendi istekleriyle seçtikleri Doğa Sporları dersi öğrencileridir. Katılımcılara çalışma öncesinde yapılacak araştırma hakkında detaylı bilgi verilerek katılımcı onam formu imzalatılmıştır.

\section{Veri toplama araçları}

Veriler yaş, cinsiyet ve spor branşı olmak üzere toplam üç soruluk demografik bilgi formu, Alana Özgü Risk Alma Ölçeği- Kısa Formu (DOSPERT) ve Eleştirel Düşünme Eğilimleri Ölçeği (KEDEÖ) ile toplanmıştır.

\section{Alana Özgü Risk Alma Ölçeği-Kısa Formu (DOSPERT)}

Bireylerin risk alma davranışlarını ölçen ve ilk olarak Weber, Blais ve Betz (2002) tarafından geliştirilen, 2006 yılında Blais ve Weber tarafindan kısa formu oluşturulan "DOSPERT (A-DomainSpecific Risk Taking- Short Form) orijinali 5 alt boyutta toplam 30 ifadeden oluşan ölçeğin Türkçe uyarlaması 5 alt boyutta 25 madde oluşmakta ve 7'li likert ile değerlendirilmektedir. Ölçeğin tamamına veya her bir alt boyuta ilişkin toplam puana göre çalışır ve ölçekte yüksek puanlar yüksek risk alma eğiliminde olarak değerlendirilir. Ölçeğin Türkçe uyarlama çalışmasında gerçekleştirilen DFA (uyum indeksi değerleri $\chi 2=548, \chi 2 / \mathrm{sd}=2.17$, RMSEA $=.04, \mathrm{GFI}=.93$, AGFI $=.91, \mathrm{CFI}=.93$ ) sonrası iç tutarlılık katsayıları (Cronbach Alpha $(\alpha)$ etik.78, finansal.78, sağlık/güvenlik .76, rekreasyonel .78, sosyal .75, toplam ölçek .86) olarak bulunmuştur (Yavaş Tez ve Dinç, 2017).

\section{Eleştirel Düşünme Ĕ̆gilimleri Ölçeği (KEDEÖ)}

Amerikan Felsefe Derneği tarafindan düzenlenen Delphi projesi sonucunda Facione (1990) tarafından geliştirilmiş ve Kökdemir (2003) tarafindan Türkçe 'ye uyarlaması yapılmıştır. Ölçeğin orijinalinde, "Doğruyu Arama", "Açık Fikirlilik", "Analitiktik", "Sistematiklik", "Kendine Güven", "Meraklılık", "Olgunluk" olmak üzere yedi alt boyut vardır ve ölçek altılı likert tipinde olup toplam 75 maddeden oluşmaktadır. Ölçeğin Türkçe'ye çevrilmesinden sonra "Olgunluk" alt boyutu "Açık Fikirlilik" alt boyutu ile birleşmiş, alt boyut sayısı altı ve toplam madde sayıs1 51 olmuştur. Ölçeğin Türkçe uyarlama çalışmasında gerçekleştirilen DFA (uyum indeksi değerleri RMR $=.049, \mathrm{GFI}=.86$, $\mathrm{AGFI}=.84$ ) sonrası hesaplanan iç tutarlık katsayısı değeri (cronbach alpha; $\alpha$ ) .88 alt ölçekler için ise .61-.78 arasında değişmektedir. (Kökdemir, 2003).

\section{Veri toplama teknikleri}

Araştırmada öntest-sontest deneysel yöntem kullanılmıştır. Ön testler eğitim öncesinde ve son testler uygulama etkinliklerinin hemen sonrasında yapılmıştır. Macera eğitimi süreci 8 hafta boyunca 
birer saatlik kuramsal derslerin (ders içeriği tablo 1'de sunulmuştur) sonunda Aladağlar Milli Parkı'nda gerçekleştirilen doğa kampçıllı̆ı ve yürüyüşü, interaktif doğa oyunları ve zirve tırmanışı (3480 m) etkinliklerini içeren 5 günlük kampı kapsamıştır. Kampın süresi literatürde etkinlikleri 3 - 7 gün aralığında programlamış olan bazı çalışmalardan (Constantine, 1993; Çelebi ve Akbaba; 2002; Çetinkaya ve Ömüriş, 2017; Dinç vd., 2004; Özen vd.., 2014) yola çıkarak belirlenmiştir.

Tablo 1

Doğa sporları dersi 8 haftalık içerik programı

\begin{tabular}{cl}
\hline Hafta & Konu \\
\hline 1 & Doğa sporları ve macera eğitimine giriş; doğa ve çevre bilinci \\
2 & Maceraya katıllım motivasyonu \\
3 & Etkinlik planlaması; günlük, günaşaırrı, expedisyon \\
4 & Doğa yürüyüş̋̈; malzemeler, beslenme, çıkış-inişde tempo ve teknikler \\
5 & Doğa kampçıı̆ı̆ı; temelleri, kullanılan malzeme işgörü ve bakımı, beslenme \\
6 & Doğada yer ve yön bulma \\
7 & Doğada risk ve tehlikeler; risk ve acil durum yönetimi \\
8 & Doğada karar verme, liderlik ve grup yönetimi \\
\hline
\end{tabular}

Kuramsal eğitimler derslik ortamında görüntü ve ses sitemini içeren konu anlatımları ve kısa uygulama çalışmalarını içermiştir. Uygulama kampı ise katılımcılar için tümüyle dağlık arazide, katılımcılar için alışık olunmayan çevre şartlarında ve yerleşim yeri desteği alınmaksızın gerçekleştirilmiştir. Etkilik boyunca toplam $72 \mathrm{~km}$. doğa yürüyüşü ve tırmanış gerçekleştirilmiş, engebeli arazi şartlarından ötürü 5790m irtifa kazanılıp kaybedilmiştir.

\section{Verilerin Analizi}

Verilerin analizinde bilgisayar destekli istatistik paket programında yanılma düzeyi 05 kullanılarak gerçekleştirilmiştir. İstatistiksel analizlere karar vermeden önce verilerin normal dağglıma uygunluğu analitik yöntemlerle (Kolmogorov-Smirnov/Shapiro-Wilk testleri), varyansların homojenliği ise Leverne Testi ile incelenmiştir. Sonuçta verilerin normal dağılım sapması anlamsız ( $>$ >.05) ve homojen olduğu belirlenerek parametrik testler tercih edilmiştir. Bu doğrultuda verilerin tanımlayıcı istatistikleri ortalama ve standart sapma, risk alma ve eleştirel düşünme sontest-sontest değerleri arasındaki farklar bağımlı gruplarda t-testi, demografik verilere ilişkin farkları ise bağımsız gruplarda t-testi ile incelenmiştir.

\section{Bulgular}

Analiz sonuçlarına göre katılımcıların zaman bağlı (öntest-sontest) değişen risk alma bulguları Tablo 2'de sunulmuştur. Buna göre katılımcıların doğa ve macera eğitimi öncesi ve sonrası rekreasyonel risk alma boyutunda aldıkları puanlarda anlamlı artış $(\mathrm{t}=-2.82 ; \mathrm{p}<.01)$, etik risk alma boyutunda ise anlamlı düşüş $(\mathrm{t}=2.09 ; \mathrm{p}<.05)$ belirlenmiştir. Sırasıyla finans, sağlık-güvenlik, sosyal risk alma alt boyutları ile DOSPERT ölçek toplam puanlarında etkinlik katılımına bağlı fark anlamsizdir $(\mathrm{p}>.05)$. 
Tablo 2

Alana Özgü Risk Alma Ölçeği Alt Boyut ve Toplam Puanları Arasında Tekrarlı Ölçümlerde T-Testi Sonuçları

\begin{tabular}{|c|c|c|c|c|c|c|}
\hline & & Ölçüm & $\sum$ & $\mathrm{sd}$ & $\mathrm{t}$ & $\mathrm{p}$ \\
\hline \multirow{2}{*}{ Etik } & 1 & 5,659 & 1,838 & \multirow{2}{*}{2,091} & \multirow{2}{*}{0,043} & \\
\hline & 2 & 4,756 & 1,920 & & & \\
\hline \multirow{2}{*}{ Finans } & 1 & 13,146 & 4,912 & \multirow{2}{*}{0,480} & \multirow{2}{*}{0,633} & \\
\hline & 2 & 12,756 & 6,647 & & & \\
\hline \multirow{2}{*}{ Sağlik-Güvenlik } & 1 & 21,122 & 7,270 & \multirow{2}{*}{2,001} & \multirow{2}{*}{0,052} & \\
\hline & 2 & 19,024 & 6,623 & & & \\
\hline \multirow{2}{*}{ Rekreasyon } & 1 & 25,0 & 7,130 & \multirow{2}{*}{$-2,822$} & \multirow{2}{*}{0,007} & \\
\hline & 2 & 28,244 & 5,990 & & & \\
\hline \multirow{2}{*}{ Sosyal } & 1 & 24,902 & 7,955 & \multirow{2}{*}{$-0,913$} & \multirow{2}{*}{0,367} & \\
\hline & 2 & 26,220 & 5,217 & & & \\
\hline \multirow{2}{*}{ Toplam } & 1 & 89,829 & 19,099 & \multirow{2}{*}{$-0,374$} & \multirow{2}{*}{0,710} & \\
\hline & 2 & 91,0 & 17,451 & & & \\
\hline
\end{tabular}

Analiz sonuçlarına göre katılımcıların zaman bağlı (öntest-sontest) değişen Eleştirel Düşünme Eğilimi bulguları Tablo 3'te sunulmuştur. Buna göre Eleştirel Düşünme Eğilimi Ölçeği alt boyutlarında sırasıyla Analitiklik ( $\mathrm{t}=-2.29 ; \mathrm{p}<.05)$, Açı Fikirlilik $(\mathrm{t}=7.03 ; \mathrm{p}<.001)$, Meraklılık ( $\mathrm{t}=-$ 3.23; $\mathrm{p}<.05)$ alt boyutlarında ve Eleştirel Düşünme Eğilimi toplam puanında $(\mathrm{t}=-5.38 ; \mathrm{p}<.001)$ anlamlı artış, Kendine Güven alt boyutunda ise anlamlı düşüş $(\mathrm{t}=2.67 ; \mathrm{p}<.05)$ olduğu saptanmıştır. Sirasıyla Doğruyu Arama ve Sistematiklik alt boyutları etkinlik katılımına bağlı fark anlamsızdır ( $\mathrm{p}>.05)$.

Tablo 3

Eleştirel Düşünme Eğilimi Ölçeği Alt Boyut ve Toplam Puanları Arasında Tekrarlı Ölçümlerde TTesti Sonuçları

\begin{tabular}{|c|c|c|c|c|c|c|}
\hline & KEDEÖ & Ölçüm & $\sum$ & $\mathrm{sd}$ & $\mathrm{t}$ & $\mathrm{p}$ \\
\hline \multirow{2}{*}{ Analitiklik } & 1 & 41,561 & 6,269 & \multirow{2}{*}{$-2,291$} & \multirow{2}{*}{0,027} & \\
\hline & 2 & 44,268 & 4,935 & & & \\
\hline \multirow{2}{*}{ Açık Fikirlilik } & 1 & 38,659 & 8,996 & \multirow{2}{*}{$-7,038$} & \multirow{2}{*}{0,000} & \\
\hline & 2 & 49,951 & 7,301 & & & \\
\hline \multirow{2}{*}{ Meraklılık } & 1 & 36,878 & 6,570 & \multirow{2}{*}{$-3,238$} & \multirow{2}{*}{0,002} & \\
\hline & 2 & 40,537 & 4,940 & & & \\
\hline \multirow{2}{*}{ Kendine Güven } & 1 & 29,0 & 5,779 & \multirow{2}{*}{2,670} & \multirow{2}{*}{0,011} & \\
\hline & 2 & 25,976 & 4,992 & & & \\
\hline \multirow{2}{*}{ Doğruyu Arama } & 1 & 21,195 & 5,649 & \multirow{2}{*}{1,430} & \multirow{2}{*}{0,161} & \\
\hline & 2 & 19,439 & 4,775 & & & \\
\hline \multirow{2}{*}{ Sistematiklik } & 1 & 22,073 & 3,251 & \multirow{2}{*}{$-1,817$} & \multirow{2}{*}{0,077} & \\
\hline & 2 & 23,293 & 2,472 & & & \\
\hline \multirow{2}{*}{ Toplam } & 1 & 189,366 & 11,651 & \multirow{2}{*}{$-5,380$} & \multirow{2}{*}{0,000} & \\
\hline & 2 & 203,463 & 14,933 & & & \\
\hline
\end{tabular}


Katılımcılar (19 kadın, 22 erkek) arasında cinsiyete bağlı ortaya çıkan farklar Tablo 4'te sunulmuştur. Buna göre Alana Özgü Risk Alma Ölçeği’nden alınan etkinlik öncesi Rekreasyon risk alma alt boyutu $\left(\mathrm{t}^{1}=-6.266, \mathrm{p}<.001\right)$ ve Sosyal $\left(\mathrm{t}^{1}=-3,436, \mathrm{p}<.01\right)$ risk alma alt boyutu ile ölçek toplam puanı $\left(\mathrm{t}^{\mathrm{1}=}=5.532, \mathrm{p}<.001\right)$ açısından erkeklerin kadınlara oranla anlamlı ölçüde yüksek risk aldıkları belirlenmiştir. Etkinliğin gerçekleşmesi ardından toplanan veriler incelendiğinde ise Sağlık-Güvenlik Risk Alma alt boyutu $\left(\mathrm{t}^{2}=-2,738, \mathrm{p}<.05\right)$ ile ölçek toplam puanı $\left(\mathrm{t}^{2}=-2,612, \mathrm{p}<.05\right)$ açısından erkeklerin kadınlara oranla anlamlı ölçüde yüksek risk aldıkları belirlenmiştir. Diğer veriler açısında cinsiyete bağlı farklar anlamsızdır ( $\mathrm{p}>.05)$.

Tablo 4

Dospert Öntest - Sontestlerine Ait Alt Boyut ve Toplam Puanları Arasında Cinsiyete Bağlı Fark (TTesti) Sonuçları

\begin{tabular}{llllll}
\hline DOSPERT Ölçek & Cinsiyet & $\sum$ & $\mathrm{Sd}$ & $\mathrm{t}$ & $\mathrm{p}$ \\
\hline \multirow{2}{*}{ Etik_1 } & Kadın & 5,316 & 1,765 & $-1,113$ & 0,273 \\
& Erkek & 5,955 & 1,889 & & \\
Etik_2 & Kadın & 4,737 & 2,257 & $-0,59$ & 0,953 \\
& Erkek & 4,773 & 1,631 & & \\
Finans_1 & Kadın & 11,579 & 3,731 & $-1,966$ & 0,056 \\
& Erkek & 14,5 & 5,466 & & \\
Finans_2 & Kadın & 10,842 & 4,810 & $-1,815$ & 0,078 \\
& Erkek & 14,409 & 7,626 & & \\
Sağlık_Guvenlik_1 & Kadın & 19,105 & 7,978 & $-1,659$ & 0,106 \\
& Erkek & 22,864 & 6,266 & & \\
Sağlık_Güvenlik_2 & Kadın & 16,053 & 7,405 & $-2,908$ & 0,006 \\
& Erkek & 21,591 & 4,656 & & \\
Rekreasyon_1 & Kadın & 19,632 & 5,449 & $-6,266$ & 0,000 \\
& Erkek & 29,636 & 4,776 & & \\
Rekreasyon_2 & Kadın & 26,316 & 5,437 & $-1,984$ & 0,054 \\
Sosyal_1 & Erkek & 29,909 & 6,062 & & \\
Sosyal_2 & Kadın & 20,737 & 8,359 & $-3,436$ & 0,002 \\
& Erkek & 28,5 & 5,604 & & \\
Toplam_1 & Kadın & 25,895 & 6,437 & $-0,354$ & 0,726 \\
Toplam_2 & Erkek & 26,5 & 4,021 & & \\
\hline & Kadın & 76,368 & 15,141 & $-5,532$ & 0,000 \\
& Erkek & 101,455 & 13,886 & & \\
& Kadın & 83,842 & 17,896 & $-2,612$ & 0,013 \\
& Erkek & 97,182 & 14,806 & &
\end{tabular}

Katılımcılar arasında Eleştirel Düşünme Eğiliminde cinsiyete bağlı ortaya çıkan farklar Tablo 5'te sunulmuştur. Buna göre Eleştirel Düşünme Eğilimi Ölçeğinden alınan etkinlik öncesi ve sonrası alt boyut ve toplam puanları arasında cinsiyete bağlı farklar anlamsızdır ( $\mathrm{p}>.05)$. 
Tablo 5

Eleştirel Düşünme Eğilimi Ölçeği Öntest-Sontestlerine Ait Alt Boyut Ve Toplam Puanlar Arasinda Cinsiyete Bağlı Fark (T-Testi) Sonuçları

\begin{tabular}{|c|c|c|c|c|c|c|}
\hline KEDEÖ Alt Boyut & & & $\sum$ & $\mathrm{Sd}$ & $\mathrm{t}$ & $\mathrm{p}$ \\
\hline \multirow{2}{*}{ Analitik_1 } & Kadın & 41,684 & 7,689 & \multirow{2}{*}{0,116} & \multirow{2}{*}{0,909} & \\
\hline & Erkek & 41,455 & 4,916 & & & \\
\hline \multirow{2}{*}{ Analitik_2 } & Kadın & 45,105 & 5,353 & \multirow{2}{*}{1,01} & \multirow{2}{*}{0,319} & \\
\hline & Erkek & 43,545 & 4,543 & & & \\
\hline \multirow{2}{*}{ Acık Fikirlilik_1 } & Kadın & 28,145 & 6,08 & \multirow{2}{*}{$-0,745$} & \multirow{2}{*}{0,461} & \\
\hline & Erkek & 29,727 & 7,336 & & & \\
\hline \multirow{2}{*}{ Acık Fikirlilik_2 } & Kadın & 36,987 & 5,847 & \multirow{2}{*}{$-0,513$} & \multirow{2}{*}{0,611} & \\
\hline & Erkek & 37,875 & 5,236 & & & \\
\hline \multirow{2}{*}{ Meraklilik_1 } & Kadın & 36,316 & 6,219 & \multirow{2}{*}{$-0,505$} & \multirow{2}{*}{0,617} & \\
\hline & Erkek & 37,364 & 6,966 & & & \\
\hline \multirow{2}{*}{ Meraklilik_2 } & Kadın & 39,947 & 4,339 & \multirow{2}{*}{$-0,705$} & \multirow{2}{*}{0,485} & \\
\hline & Erkek & 41,045 & 5,455 & & & \\
\hline \multirow{2}{*}{ Kendine Güven_1 } & Kadın & 29,632 & 5,6 & \multirow{2}{*}{0,646} & \multirow{2}{*}{0,646} & \\
\hline & Erkek & 28,455 & 6,006 & & & \\
\hline \multirow{2}{*}{ Kendine Güven_2 } & Kadın & 26,211 & 4,721 & \multirow{2}{*}{0,277} & \multirow{2}{*}{0,783} & \\
\hline & Erkek & 25,773 & 5,318 & & & \\
\hline \multirow{2}{*}{ Doğruyu Arama_1 } & Kadın & 21,737 & 5,216 & \multirow{2}{*}{0,566} & \multirow{2}{*}{0,575} & \\
\hline & Erkek & 20,727 & 6,08 & & & \\
\hline \multirow{2}{*}{ Doğruyu Arama_2 } & Kadın & 19,053 & 4,696 & \multirow{2}{*}{$-0,477$} & \multirow{2}{*}{0,636} & \\
\hline & Erkek & 19,773 & 4,927 & & & \\
\hline \multirow{2}{*}{ Sistematiklik_1 } & Kadın & 22,421 & 2,714 & 0632 & 0531 & \\
\hline & Erkek & 21,773 & 3,69 & 0,052 & ו ו ונכ, & \\
\hline Sistematiklik 2 & Kadın & 23,105 & 2,904 & 0447 & 0658 & \\
\hline 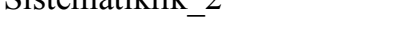 & Erkek & 23,455 & 2,087 & $-0,+4 i$ & 0,050 & \\
\hline Tonlam 1 & Kadın & 189,316 & 11,22 & 0025 & 008 & \\
\hline 10pranti-1 & Erkek & 189,409 & 12,273 & $-0,0<J$ & 0,90 & \\
\hline Tonlam 2 & Kadın & 202,737 & 14,321 & -0286 & 0.776 & \\
\hline & Erkek & 204,091 & 15,751 & & & \\
\hline
\end{tabular}

\section{Sonuç, Tartışma ve Öneriler}

$\mathrm{Bu}$ araştırma risk alma ve eleştirel düşünme eğiliminde doğa macera eğitimine katılıma bağlı anlamlı değişimlerin olup olmadığını incelemek amacıyla yapılmıştır. Çalışmanın bulgularından ilki, doğa macera eğitimlerine katılım özellikle rekreasyonel risk alma eğilimlerini arttırdığı söylenebilir. DOSPERT dikkate alındığında "rekreasyonel risk alma" alt boyutu maddelerinin macera programları içeriğindeki etkinliklere katılma eğilimi yoluyla risk alma davranışını tanımladığı görülmektedir. Katılımcılar macera etkinliklerine ilişkin algıları ve yargıları her ne kadar uygun prosedürler kullanılsa da macera etkinlikleri tehlikeli değerlendirmekte (Furlang vd., 1995; Akt: Pries ve Gass, 2018) olduğu yargısı, hemen bütün acemi macera katılımcıları için geçerli bir durum teşkil etmektedir (Lipscombe, 2007). Hatta macera etkinliklerinin geleneksel fiziksel aktivitelerden çok daha güvenli olduğunu gösteren araştırma sonuçlarına rağmen durumda bir değişiklik olmamaktadır (Pries ve Gass, 2018). Bunun tek istisnası zor olarak algılanan ve hedefleri başarıyla gerçekleştirilen doğa sporları etkinliklerinden sonra gerçekleşen durumdur. Fave, Bassi ve Massimini (2003), risk algısının etkinlik 
süresince artmasına rağmen başarılı deneyimlerin gerçekleşmesinin dağcılık gibi etkinliklerde flow (akış durumunu) (Csikszentmihalyi, 1992) ortaya çıkardığını belirterek bilinçlilik ve zaman duygusunun değiştiği savunmaktadır. Bu duygu durumu sonucunda katılımcıların kendisiyle ilişkili aktiviteyi tekrarlama eğiliminde yarattığını, kendilerini uygulama yapmaya ve tekrar deneyimlemelerine izin veren durumları aramasına neden olur. Dolayısıyla deneyim algısına bağlı olarak risk algısı azalır ve risk alma eğilimi artış gösterebilir. Bu durum, Martin ve Priest (1986) tarafindan tanımlanan Macera Eğitim Paradigması'nda açıklanan duruma paralellik göstermektedir. Dolayısıyla çalışma sonucunda ulaşılan bulgular sonucunda macera kamp deneyimiyle bireyler zor ve tehlikeli olarak düşündüğü etkinliklerin kendisi için ulaş1labilir ve gerçekleştirilmesi daha olası olarak algılaması, risk alma eğilimi arttırabileceğini ifade etmektedir. Bunun yanısıra doğada gerçekleştirilen etkinliklerin katılımcılarda iyi olma hali (Pretty, Peacock, Sellens ve Murray, 2003) desteklediği,olumlu duygu durumu yarattığ artış (Özen vd., 2014) yarattığı bildirilmiştir. Çelebi, (2002) bu durumun doğada kazanılan deneyime bağlı olarak bireyin sosyal-psikolojik kazanımlarında artış sağladığını belirtmiştir. Katılımcılarda rekreasyonel risk alma yönündeki artışın gözlenmesinin bir diğer nedeni bu öz yeterlik veya etkililik gibi psiko-sosyal kazanımlarda ortaya çıkan gelişmenin bir sonucu gibi algılanabilir.

Çalışma bulgularında ortaya çıkan risk alma düzeyleri arasındaki cinsiyet farklılığı, risk alma konusundaki cinsiyet farklılıkları analiz eden çalışmaların hemen tümünde (Byrnes, Miller ve Schafer, 1999; Demirhan, 2005; Demirhan vd., 2014; Dinç vd., 2004; Schrader ve Wann, 1999) benzer biçimde ortaya konmuştur. Buna göre erkeklerin kadınlardan daha yüksek risk alma eğiliminde olduğu, çalışmamız sonuçlarını destekler biçimde ortaya konmuştur. Çalışmamızın cinsiyet farklılığına ilişkin dikkate değer diğer bulgularından birisi de kadın katılımcıların risk alma alt boyut ve toplam puanların tamamında yükselmenin gözlenmesidir. Bu durum, Jones, Hollenhorst ve Perna (2003) tarafından ifade edilen doğada yaşanabilecek zorlukları yenmelerine engel olan korkunun üstesinden gelebilmek üzere bir tür zihinsel dayanıklılık gelişimi olarak tanımlanabilir. Kendileri için zor bir çevre oluşturan doğadaki macera ortamında kadınların diğer sosyal çevrelere göre, güvenin önemli olduğu tırmanma grubunda daha fazla kabul görmeleri (Dilley ve Scraton, 2010), başlangıçta erkeklerden anlamlı biçimde düşük olan sosyal risk alma eğilimlerini yükseltmiş olabilir.

Araştırma katılımcılarının eleştirel düşünme eğilim düzeylerinin düşük olduğu söylenebilir. Çünkü ölçekten alınan toplam puanlar dikkate alındığında 240'dan düsük puan alanlarin düsük elestirel düşünme eğilimlerine sahip olduklari ifade edilmektedir. Bu durum farklı alanlara ilişkin ögretmenlik programlarında (Grosser ve Lombard, 2008; Gülveren, 2007) gerekse öğretmenlik dışındaki programlarda (Dayıoğlu, 2003; Shin, Ha, Shin ve Davis, 2006) öğrenim gören üniversite öğrencileri ile yapılmış olan çalışmalarda öğrencilerin eleştirel düşünme becerilerinin olmas gerektiği düzeyin altında olduğu ve genellikle orta düzeyde eleştirel düşünme becerisine sahip oldukları verisiyle örtüşmeyen bir durumdur. Ancak Gülveren (2007) ve Saçlı ve Demirhan (2008) yaptıkları çalışmalarda birinci sınıf öğrencilerinin eleştirel düşünme eğilimlerinin okul yaşamının en düşük döneminde olduğunu ve sınıf düzeyi ile birlikte eleştirel düşünme becerilerinde anlamlı artış olacağını ortaya koymuştur. $\mathrm{Bu}$ anlamda eğitime katılan birinci sınıf öğrencileri için düşük düzey beklenebilecek bir durum olduğu söylenebilir.

Katılımcıların analitiklik, açık fikirlilik, meraklılık alt boyutlarında ve ölçek toplam puanları doğa macera eğitimi sürecinde artış göstermiştir. Kendine Güven alt boyutunda ise anlamlı düşüş olduğu belirlenmiştir. Eleştirel düşünme eiliminin farklı eğitim programlarında öğrenim gören öğrencilerin ileriki sınıflarda artı̧̧ göstermesi, araştırma sonuçlanıla ortaya konmuştur (Grosser ve Lombard, 2008; Gülveren, 2007; Shin vd., 2006; Dayığlu, 2003; Saçlı ve Demirhan, 2008). Bu anlamda üniversite eğitimi içeriğinde yer alan macera eğitimi programının anlamlı değişimler yaratması paralel bir sonuç olarak görülmektedir. Ayrıca macera terapisi yaklaşımıyla (Ewert, McCormick ve Voight, 2001) oluşturulan ideal zorluk düzeyinde planlanan macera etkinlikleri yoluyla bireyde ortaya çıkan başarma duygusunun getirdiği öz yeterlik, eleştirel düşünme becerisine transfer edilmiş gözükmektedir. Çünkü artan beceri seviyesi uzmanlık, güven veya öz-yeterliliğin artmasına yol açar (Caldwell, 2001). Son zamanlarda yapılan araştırmalar, ergenlere yönelik teorik olarak tasarlanmış programlarda doğada kazanılan etkinlik becerilerinin akademik etkinliğe 
genellenebileceğini göstermekte, kendine güven alt boyutundaki azalma ise bireylerin korkuyla ilişkili yüksek düzeyde uyarılma (Taniguchi, 2017) yaşamasından kaynaklı olabileceği düşünülmektedir.

Eleştirel düşünce eğilim düzeylerinde cinsiyete göre fark olmaması literatürde yer alan araştırmalarla örtüşen bir sonuçtur. Eleştirel düşünme eğilimi'nin cinsiyeti bağımsız değişken olarak ele alındığ 1 çalışmalarda göre incelendiği araştırmalarda (Dayığlu, 2003; Gülveren, 2007) eleştirel düşünmenin cinsiyetten bağımsız bir beceri olduğu, cinsiyetin üniversite öğrencilerinin eleştirel düşünme beceri düzeylerinde anlamlı bir farka yol açmadığı ifade edilmiştir.

Sonuç olarak macera eğitim sürecinin katılımcılarda risk alma düzeyi artış yarattığı, erkeklerin kadınlara oranla daha yüksek risk aldıkları, eğitim sürecinin her iki cinsiyette de artış yarattığı, eleştirel düşünme eğilimlerinde artışa neden olduğu ancak cinsiyetler arasında fark yaratmadığ söylenebilir.

Araştırma bir takım sınırlllıkları içermektedir. Öncelikli olarak örneklem seçimi itibariyle sıklıkla tercih edilmeyen doğa sporları dersini seçen öğrencilerin tek başına araştırma grubunu oluşturması en önemli sinırlılıktır. Rekreasyonel gruplar arasında doğa etkinliklerine katılım gösteren ve belirli bir süre kulüp, dernek çalışmalarına devam eden bireylerin katılımının sağlanması örneklem seçme yöntemini değiştirebilir. Etkinlik planlaması gruba uygun zorlukları içerecek biçimde yapılandırımasına karşın, etkinlik sürecinin kısıtlı gün aralığında tutulmasını gerektirmiştir. Ayrıca etkinliğin kamp taşıma faaliyetini kısıtlayan tekbir bölgede icra edilmesi bir diğer kısıtlılıktır. $\mathrm{Bu}$ aşamadan sonra yapılacak çalışmalarda diğer değişkenlerin etkisinin de incelenebilmesi için üniversite eğitim sürecinden bağımsız bir grupla çalışılması, kontrol grubuyla değişim etkisinin incelenmesi ve macera programlarının diğer örnekleriyle veriler arasındaki kolaylaştıııcı model etki çalışılmaları önerilmektedir.

Teşekkür ve/veya Açıklamalar: Bu çalışmanın özeti "Doğa macera eğitiminin risk alma ve eleştirel düşünme üzerine etkisinin incelenmesi" adıyla 01.11.2018 tarihinde Antalya'da yapılan 16. Uluslararası Spor Bilimleri Kongresi'nde sunulmuştur. 


\section{Kaynaklar}

Byrnes, J. P., Miller, D. C. ve Schafer, W. D. (1999). Gender differences in risk taking: A metaanalysis. Psychological Bulletin, 125, 367-383.

Brymer, E. ve Schweitzer, R. (2013) Extreme sports are good for your health: a phenomenological understanding of fear and anxiety in extreme sport. J Health Psychology 18(4), 477-87. doi: $10.1177 / 1359105312446770$

Brown, I. D. (1989). Managing for adventure recreation. Australian Parks and Recreation, 25(4), 3740

Caldwell, L. (2001). Reflections on therapeutic recreation and youth: Possibilities for broadening horizons. Therapeutic Recreation Journal, 35, 279-288.

Cater, C. I. (2006). Playing with risk? Participant perceptions of risk and management implications in adventure tourism. Tourism Management, 27, 317-325.

Chen, W. ve Cone, T. (2003). Links between children's use of critical thinking and an expert teacher's teaching. Creative Dance, 22(2), 169-185.

Constantine M. (1993). The effects of ropes course experience on perceived self-efficacy: A study designed to examine the effects of an adventure program. The Pennsylvania Journal of health, Physical Education, Recreation and Dance. 52(2), 10.

Csikszentmihalyi, M. (1992). "Flow”:The psychology of happiness. London: Rider, p. 6-7

Cüceloğlu, D. (2008). İyi düşün doğru karar ver, İstanbul: Remzi Kitapevi

Çelebi M. (2002). Doğa etkinliklerinin, liderlik becerilerinin ortaya çıkarılmasındaki rolü. Yayımlanmamış Doktora Tezi, Abant İzzet Baysal Üniversitesi, Sosyal Bilimler Enstitüsü, Bolu.

Çelebi, M. ve Özen, G. (2004) University students and adventure education programmes: A Study of meanings and experience of adventure training activities, International Conference on Leisure, Tourism \& Sport Education, Integration, Innovation, Gologne, German,

Çelebi, M. ve Akbaba A. S. (2002) Nitel araştırma yöntemi ile güven ve risk alma becerilerinin doğa etkinliklerinde ortaya çıkarılması, 2. Doğa Sporları ve Bilim Sempozyumu Bildiri Özetleri Kitapçı̆̆g, Hacettepe Üniversitesi, Ankara.

Çetinkaya, G. ve Ömüriş, E. (2017) Doğa sporları aktivitelerine katılan bireylerin olumlu ve olumsuz duygulanım durumlarının incelenmesi, Uluslararasi Spor, Egzersiz ve Antrenman Bilimi Dergisi, 3(3), 76-85

Dayığlu, S. (2003). A Descriptive study on the critical thinking levels of the students at the unit of english preparatory school at Hacettepe University. The Degree of Master of Science, Middle East Technical University. The Department of Educational Sciences

Demirhan, G. Aşçı, F. H. Kangalgil, M. ve Saraçbaşı, O. (2014). Perception of risk and attractiveness of extreme sports among turkish university students, Spor Bilimleri Dergisi, 25(1), 11-22

Demirhan, G. (2005). Mountaineers' risk perception in outdoor-adventure sports: a study of sex and sports experience, Perceptual and Motor Skills, 100, 1155-1160.

Dinç, S. C. (2006). Doğa sporları etkinliklerine ilişkin liderlik ölçeğinin geliştirilmesi, Yayımlanmamış Doktora Tezi, Hacettepe Üniversitesi Sağlık Bilimleri Enstitüsü, Ankara. 
Dinç S. C. Koca, C. Demirhan, G. ve Aşçı, H. (2004) An investigation of risk perception and risk views of male and female university students before and after participating the outdoor activities experience The 10th ICHPER-SD Europe Congress \& The TSSA 8th International Sports Science Congress Abstract Book (p. 43-44) Antalya: Spor Bilimleri Derneği.

Dilley, R.E. ve Scraton, S.J. (2010) Women, climbing and serious leisure. Leisure Studies, 29, 125141

Ewert, A. W. (1989). Outdoor adventure pursuits: Foundations, models, and theories. Columbus, OH: Publishing Horizons, Inc.

Ewert, A. W. (2007). Leisure, Recreation, and Adventure: A multidimensional relationship Annals of Leisure Research 10(1), 1-2.

Ewert, A.W. ve Hollenhorst, S. (1995). Adventure recreation and its implication for wilderness. International Journal Of Wilderness. 3(2).

Ewert, A., McCormick, B. ve Voight, A. (2001). Outdoor experiential therapies: Implications for TR practice. Therapeutic Recreation Journal, 35, 107-122.

Ewert, A.W. ve Sibthorp, J. (2014). Outdoor adventure education: foundations, theory and research. Champaign, IL: Human Kinetics, 79-83.

Gillespie, L. ve Culpan, I. (2000). Critical thinking: ensuring the 'education' aspect is evident in physical education. Journal of Physical Education New Zealand. 33(3), 84-96.

Grosser M. M. ve Lombard B.J. (2008). The relationship between culture and the development of critical thinking abilities of prospective teachers. Teaching and Teacher Education, 24(5), $1364-1375$

Gülveren H. (2007). Eğitim fakültesi ögrencilerinin eleştirel düşünme becerileri ve bu becerileri etkileyen eleştirel düşünme faktörleri, Yayımlanmamış Doktora Tezi, Dokuz Eylül Üniversitesi. Eğitim Bilimleri Enstitüsü, İzmir.

Hayran, M. ve Hayran, M. (2011). Sağlık araştırmaları için temel istatistik. Ankara: Omega Araştırma.

Hardiman, N. ve Burgin, S. (2011) Canyoning adventure recreation in the Blue Mountains World Heritage Area (Australia): The canyoners and canyoning trends over the last decade Tourism Management 32, 1324-1331.

Jones, C. Hollenhorst, S. ve Perna, F. (2003). An Empirical comparison of the four channel flow model and adventure experience paradigm, Leisure Sciences, 25, 17-31.

Kökdemir, D. (2003). Belirsizlik durumlarında karar verme ve problem çözme, Yayımlanmamış Doktora Tezi, Ankara Üniversitesi Sosyal Bilimler Enstitüsü, Ankara.

Llewellyn, D. J. ve Sanchez, X. (2008). Individual differences and risk taking in rock climbing. Psychology of Sport and Exercise, 9, 413-426.

Martin, P. ve Priest, S. (1986). Understanding the adventure experience. J. of Adventure Education, $3(1), 18-21$

McBride, R. Gabbard, C. ve Miller, G. (1990). Teaching critical thinking skills in the psychomotor domain. Clearing House, 63(5), 197. 
Mutlu, F. Polat, E. İlçin, M. ve Kalkan, T. (2016). Beden eğitimi ve spor yüksekokulu öğrencilerinin eleştirel düşünme eğilimlerinin bazı değişkenler açısından incelenmesi (Niğde ili örneği), Spor Bilimleri Araştırmaları Dergisi 1(1), 27-36.

Özden, B. (2005). Eğitim fakültesi ilköğretim bölümü anabilim dalı programlarının eleştirel düşünme becerilerinin gelişimine etkisi, Yayımlanmamış Yüksek Lisans Tezi, Yıldız Teknik Üniversitesi, Sosyal Bilimler Enstitüsü, İstanbul.

Özen, G. Özen, Ş. Sönmez, G.T. (2014) Kamp yaşantısı ve engel aktivitelerinin katılımcıların öz etkililik algılarına etkisi, Spor ve Performans Araştırmaları Dergisi (5)2, 5-12.

Pain, M. G. ve Pain, M. A. (2005). Essay: Risk taking in sport. The Lancet, (1), 366.

Paul, R. W. ve Elder, L. (2001). Critical thinking-tools for taking care of your learning and your life, Prentice Hall, NJ.

Pretty, J., Peacock, J., Sellens, M. ve Murray, G. (2005). The mental and physical health outcomes of green exercise. International Journal of Environmental Health Research, 15, 319-337. doi:10.1080/09603120500155963.

Priest, S. ve Gass, M. A. (2018). Effective leadership in adventure programming, third edition, Champaign, Illinois: Human Kinetics. 13-60.

Saçlı, F. ve Demirhan, G. (2008). Beden eğitimi ve spor öğretmenliği programında öğrenim gören öğrencilerin eleştirel düşünme düzeylerinin saptanması ve karşılaştırılması. Spor Bilimleri Dergisi, 19(2), 92-110.

Schrader, M. P. ve Wann, D. L. (1999). High-risk recreation: The relationship between participant characteristics and degree of involvement. Journal of Sport Behavior, 22, 426-441.

Sibthorp, J. (2003) An empirical look at Walsh and Golins' adventure education process model: Relationships between antecedent factors, perceptions of characteristics, Journal of Leisure Research, 35, 80-106.

Shin, S. Ha, J. Shin, K. ve Davis, M. K. (2006). Critical thinking ability of associate, baccalaureate and RN-BSN senior students in Korea. Nursing Outlook, 328-333.

Şenşekerci, E. ve Bilgin, A. (2008). Eleştirel düşünme ve öğretimi, UÜ. Fen-Edebiyat Fakültesi Sosyal Bilimler Dergisi Y11:9 Say1:14.

Tishman, S., Perkins, N. D. ve Jay, E. (1995). The thinking classroom: Learning and teaching in a culture of thinking. Boston: Allyn and Bacon.

Tsangaridou, N. ve O'Sullivan, M. (1994). Using pedagogical reflective strategies to enhance reflection among preservice physical education teachers. Journal of Teaching in Physical Education, 14(1), 13-33.

Fave, A. Bassi, M. ve Massimini, F. (2003). Quality of experience and risk perception in high-altitude rock climbing. Journal of Applied Sport Psychology, 15, 82-98.

McBride, R. (1992). Critical thinking - an overview with implications for physical education. Journal of Teaching in Physical Education, 11, 112-125.

Taniguchi, S.T. Bennion, J. Duerden, M. D. Widmer M. A. ve Ricks M. (2017). Self-Efficacy of risk taking in outdoor recreation as a predictor of the self-efficacy of risk taking in essay writing, Leadership, 9(4), 425-438. https://doi.org/10.18666/JOREL-2017-V9-I4-8653. 
Tishman S. ve Perkins D. N. (1995). Critical thinking and physical education. Journal of Physical Education, Recreation \& Dance, 66 (6), 24-31.

Tobena, A. Marks, I. ve Dar, R. (1999). Advantages of bias and prejudice: An explanatio of -their neurocognitive templates. Neuroscience and Biobehavioral Review, 23, 1047- 1058.

Yavaş Tez, Ö. ve Dinç S. C. (2017) Alana özgü risk alma ölçeği- kısa formu'nun (dospert) Türkçeye uyarlama çalışması, Dünya Spor Bilimleri Araştırmaları Kongresi Bildiri Özetleri Kitabı içinde (SB413), Manisa.

Walsh, V. Ve Golins, G., (1976). The exploration of the outward bound process, Outward Bound School, Denver. 


\section{Extended Abstract}

\section{Introduction}

Over the past two decades, participation rates in extreme sports and their fewer extreme cousins have grown rapitly than many traditional sporting activities (Pain and Pain, 2005). They have become popular weekend and vacation activities for anyone today, while a few numbers of professionals have already been engaged in the past (Brymer and Schweitzer; 2013; Pain and Pain, 2005). Outdoor adventure recreation is defined as a deliberate struggle situation created through specially developed skills and decision-making practices in a natural environment that contains uncontrollable dangers (Brown, 1989,). Individual characteristics, capabilities, preferences, past experiences and expectations, program objectives, activities, real or perceived danger and social and environmental factors come together to produce ambiguous results (Ewert and Sibthorp, 2014). Outdoor adventure education is a teaching method that involves the use of all senses by including an experiential process in the natural field. Therefore, it examines the interdisciplinary issues involving natural resources and human relations. While outdoor adventure education improves social and physical adaptation, it improves the participants' self-confidence in problem solving, free thinking and learning. These characteristics, which are the key to cognitive and emotional development, reveal the development of skills in decision making, judgment, and alternative solutions to problems. In the light of the Adventure Paradigm (Martin and Priest, 1986; Priest ve Gass, 2018), the individual's decision to take the risks related to his / her competence by evaluating his / her experience in the environment of the activity, may give opportunity to the development of critical thinking mechanism. Critical thinking can be expressed as a way of thinking which requires taking into account scientific facts and situational variables before making a judgment on any subject in the process of interaction of the individual with both social and natural environment (Şenşekerci and Bilgin, 2008). The use of critical thinking in physical education provides broad and adventurous thinking, finding innovative solutions, making a comparison by reason and evaluative reasoning, planned and strategic thinking, metacognition and use to make logical and defensible decisions in the face of movements and challenges (McBride, 1992; Tishman and Perkins, 1995). Critical thinking education aims to provide students with the ability to make decisions about what they want to do and live, to be effective, to examine events and facts from a different point of view (Şenşekerci and Bilgin, 2008). Outdoor adventure education programs also provide these features by developing incoherent situations that adapt to collaborative group work (Priest and Gass, 2018). In this context, the purpose of the study was to examine whether there were meaningful changes in risk taking and critical thinking dispositions after the participation in outdoor adventure education.

\section{Method}

A total of 41 university students, 19 female $(\overline{\mathrm{x}}$ age $=20.21 \pm 1.96)$ and 22 male $(\overline{\mathrm{x}}$ age $=19.90 \pm$ $1.41)$, voluntarily participated in the study. The adventure education was a 5-day experience that included outdoor camping and trekking, interactive games and summit climbing $(3480 \mathrm{~m})$ in the Aladağlar National Park after 8-week theoretical course one hour each. The data were collected as preposttest with demografik variable form, Domain-Specific Risk-Taking (DOSPERT) Scale and Critical Think Thinking Disposition Inventory (CCTDI)

Domain Specific Risk Assessment Scale -Short Form (DOSPERT) developed by Blais and Weber (2006) adopted to Turkish by Yavaş Tez ve Dinç (2017). DOSPERT Scale evaluate behavioral intentions or the likelihood with which respondents might engage in risky activities/behavioursoriginating from five domains of life with 5 sub-dimensions that contain 6 item each (ethical, financial, health/safety, recreational and social risks). The domain risk-taking behaviour responses of participants are assessed by using a 7-point rating scale (Weber ve Blais, 2006). Cronbach Alpha $(\alpha)$ ethical .78, financial .78, health/safety .76, recreational .78, social .75, and total scale .86 . 
Critical Think Thinking Disposition Inventory (CCTDI) was developed by Facione (1990) as a result of the Delphi project organized by the American Philosophical Society and adapted to Turkish by Kökdemir (2003). The CCTDI measures seven attributes that influence an individual's capacity to learn and to effectively apply critical thinking skills (Truthseeking, Open-mindedness, Analyticity, Systematicity, Confidence in Reasoning, Inquisitiveness and Maturity of Judgment) The original of the scale is six-point Likert type and consists of 75 items. After the translation of the scale into Turkish, the bir Maturity, sub-dimension was combined with the "Open-mindedness" subdimension, and the total number of items was 51 . The Cronbach's alpha value for .880 subscales varies between $\alpha=.61$ and .78 (Kökdemir, 2003: 41).

Before deciding the statistical analysis, the appropriateness of the data to the normal distribution was analysed by analytical methods (Kolmogorov-Smirnov / Shapiro-Wilk tests), and the homogeneity of the variances was analysed by Leverne Test. As a result, the normal distribution deviation of the data was meaningless $(\mathrm{p}>.05)$ and homogeneous and parametric tests were preferred. In this respect, the descriptive statistics of the data were analysed by means of standard and standard deviation, and paired t-test was used to analyse pro-test and post-test values of critical thinking and risk taking, and t-test.was used to analyse differences in demographic data by critical thinking and risk taking.

\section{Results}

There was significant increase in recreational risk taking $(\mathrm{t}=-2.82 ; \mathrm{p}<.01)$, while significant decrease in ethical dimension $(\mathrm{t}=2.09 ; \mathrm{p}<.05)$ of the DOSPERT from pre-test to post-test. There were significant increases in analyticity $(\mathrm{t}=-2.29 ; \mathrm{p}<.05)$, open-mindedness $(\mathrm{t}=7.03 ; \mathrm{p}<.001)$, inquisitiveness $(\mathrm{t}=-3.23 ; \mathrm{p}<.05)$ and total scores $(\mathrm{t}=-5.38 ; \mathrm{p}<.001)$ while significant decrease in selfconfidence $(\mathrm{t}=2.67 ; \mathrm{p}<.05)$ of CCTDI, respectively. It was seen that male participants had significantly higher scores than females in risk taking in both measures $\left(t^{1}=-5.53, p<.001 ; t^{2}=-2.61, p<.05\right)$. Regarding critical thinking disposition, there were no significant differences either in sub-dimension or total scores $\left.\mathrm{t}^{1}=-.25, \mathrm{p}>.05 ; \mathrm{t}^{1}=-.28, \mathrm{p}>.05\right)$. of CCTDI according to gender $(\mathrm{p}>.05)$.

\section{Conclusion and Discussion}

As a result, it can be said that outdoor adventure education had positive changes in risk taking and critical thinking dispositions at university students and male students took more risks than females in outdoor. 